\title{
A Case Study of the Commercially Published ELT materials in Foundation of English Course Books 1 \& 2
}

\author{
Md. Yousuf Uddin Khaled Chowdhury*
}

\begin{abstract}
Brumfit (1979) has suggested that many commercially published ELT materials are little more than 'masses of rubbish, skilfully marketed'. He perhaps rejects most of the published materials. However, in reality, it is observed that these ELT resources are the only available alternatives in the contexts where infra-structural limitations of language classrooms and the inefficiency of the language-teachers make the goal of language learning and teaching unreachable or unattainable for many of the learners. This paper, through a case study, aims at justifying the use of commercially published ELT coursebooks that are designed and used, considering the limitations and problems of the personally produced materials by untrained teachers. Nevertheless, these materials must consider the local market rather than the global markets so that they meet the needs of the local language learners and instructors. The case study implies that it is the selection or adaptation of the right materials for the specific learners that makes them effective or ineffective. It also suggests that the personally designed or locally produced materials too may make teaching and learning difficult and impossible sometimes.
\end{abstract}

\section{Introduction}

The selection of an appropriate course book that meets the needs of the learners and the goals of teaching and learning is a prerequisite for all academic situations, and it is more crucial and difficult in language

\footnotetext{
${ }^{*}$ Lecturer, Dept. of English Language \& Literature, International Islamic University Chittagong.
} 
teaching and learning. Moreover, if the language is a second language (SL hereafter) or a foreign language (FL hereafter), the selection becomes more problematic. The process of selection depends on the evaluation methods that requires judicious consideration based on analysis, experiment and experience. In an English as a second language (ESL hereafter) or English as a foreign language (EFL) situation, the selection of perfect English Language Teaching (ELT hereafter) materials is quite puzzling because of the availability of materials from different sources such as renowned ELT publishers in the native English speaking countries which are considered authentic, websites, locally produced ELT materials that are proclaimed as the best resources for local users or consumers etc. Block (1991: 211 ) realizes the fact when he says,

$$
\begin{aligned}
& \text { '[...] whereas fifteen years ago a teacher might well } \\
& \text { complain about the unavailability of materials to } \\
& \text { practice this or that structure or this or that } \\
& \text { vocabulary field, today, with the plethora of language } \\
& \text { teaching materials on the market the problem often } \\
& \text { seems to be one of knowing what to choose in a } \\
& \text { veritable land of plenty. }
\end{aligned}
$$

Being biased by the publicity or by being forced to choose from the available materials because of unwillingness or incapability to produce their personal materials, most of the teachers select any one or some of them as the perfect course book(s) for their teaching situations. By doing so, they ignore and neglect the demand to develop materials of their own that are supposed to be based on the situational and contextual needs. Sheldon (1988:238) says,

\begin{abstract}
'The sheer labour-intensiveness of developing classroom materials, the pressure of heavy time-tables and the highly restrictive nature of most teaching situations nevertheless force the teacher (or educational purchaser) to rein his or her reservations, and choose a book which only approximates to the needs of the local context'.
\end{abstract}

It is equally true that despite the availability of published ELT materials, teachers still look for more materials that suit their class as 'published materials do not always provide the types of texts and activities that a teacher is seeking for a given class (Block 1999: 211)'. 
Teachers most often reshape the lessons in the course books that are produced without considering the specific culture, tradition, linguistic background, socio-economic status etc. of the learners. Hutchinson and Torres state, 'Most often teachers follow their own scripts by adapting or changing textbook based tasks, adding new texts or deleting some, changing the management of the tasks, changing task inputs or expected outputs and so on' (Hutchinson and Torres 1994: 325). Sheldon (1988:237) observes a 'poor compromise between the academic expectations and the affordability of the educational purchasers' as the published materials 'often do not seem to provide good value for money'. 'The coursebook credibility gap' (Greenall 1984: 14) makes the commercially produced ELT materials lucrative but ineffective and unusable for ultimate classroom use. Brumfit (1980:30) states that 'masses of rubbish is skillfully marketed.'

This paper aims at evaluating a commercially produced ELT book designed for undergraduate students in a private university in Bangladesh in the light of Brumfit's (1980:30) comment suggesting that many commercially published ELT materials were little more than 'masses of rubbish, skilfully marketed'. The following sections will discuss the merits and demerits of published materials. The selection and the evaluation criteria of ELT materials occupies a major area in the discussion. The discussion will contribute to the evaluation of 'Foundation of English Coursebook 1 and 2' in a separate section that will be followed by the conclusion arguing why Brumfit (1980:30) is not fully acceptable regarding the materials produced keeping the specific needs of particular learner groups in mind.

\section{Literature Review:}

ELT materials play a vital and positive role in the teaching and learning process, particularly in a situation where trained teachers are not available in an ESL or EFL context. In such a situation 'language teaching is closely tied to text book' (Williams 1983:251). A textbook or course book facilitates the teaching and learning process by providing examples of common difficulties faced by learners. Despite the controversy over the roles of commercially produced ELT materials, the importance of ready- made course books and materials in formal educational situation still exists. Hutchinson and Torres (1994: 317) suggest that publication of course books will be continued as they are the easiest source of structures required by the teaching and learning system. The significance of these materials cannot be ignored 
albeit the limitations in them sometimes make some parts questionable to use. It implies the necessity of the proper selection and evaluation and adaptation of the teaching materials that meet the needs of teachers and learners.

A critical study of the available literatures related to materials development, selection and evaluation suggests certain factors to be considered keeping the specific needs in mind. The materials mustmeet the learners' and teachers' needs ( Dow 2004; Howard and Major 2004). It means that a skillful materials designer identifies the learners' language background, their level of proficiency, their learning objectives and preferred learning style. They must be coherent with the curriculum and the syllabus of the learners and supplemented by additional facilities and resources (Howard and Major 2004). They must not violate the copy right laws. They should reflect the teachers' instructional objectives. These objectives are specific outcome- based, measurable and describe the learners' behavior after instructions. (O' Bannon 2002). They need to comply with teachers' personal teaching preference style that suits his personality. (Dow 2004) They must be flexible and adaptable.

Besides these factors, Howard and Major (2004) think that a set of good teaching materials should be contextualized to the curriculum, experiences, realities and the first language of learners; to topics and themes that provide meaningful and purposeful uses of the target language . It must encourage learners to develop personalized learning skills and strategies through interaction. It should have appropriate instructions from teachers and learners regarding the uses of materials.

Harmer (2001:7) suggests that 'good course books offer students (and teachers) a coherent syllabus, the result of many years of experience and much research and discussion with teachers, consultants and publishers. It also reflects the exact position of teacher and provides feelings of progress and security to students with their systematic use of the book. Nunan (1991:209) states, 'The selection process can be greatly facilitated by the use of systematic evaluation procedure which ensures that materials are consistent with the needs and interest of learners they are to serve, as well as being in harmony with ideologies on the nature of language and learning. Evaluation of materials relates the materials and the users on the basis of needs, techniques of use, potential minimum outcome, and functional appropriateness. Effective 
evaluation of materials relies on appropriate questions and interpreting the answers to them (Cunningsworth 1995).

The checklist made by Cunningsworth consists of forty five questions on a wide range of issues such as skills, aims, design, language content, methodology, cost and affordability, motivation, supporting materials, Selection and grading of language items, presentation and practice of new language items etc. Sheldon (1998: 238) also provides a checklist in which layout and authenticity, accessibility and cultural issues etc. are emphasized, He includes gender, race, social class and nationality issues in line with Harmer (2001) and McDonough and Shaw (2003). The issue of cultural bias is innovative in his framework. He asks if the materials provide 'stereotyped, inaccurate, condescending or offensive images of gender, race, social class, and nationality. In his evaluative scheme based on four assumptions which are up- to- date methodology, guidance for nonnative teachers, needs of second language learners, and relevance to the socio-cultural environment. Williams (1983: 251-253) refers to the consistency of the materials with the psychological and linguistic principles regarding second language teaching. It is to be noted that the checklist or the criteria proposed by them are not exhaustive. The process of evaluation cannot be purely mechanical and thus it requires professional judgments. Cunningsworth (1984:74) says, 'Professional judgment founded on understanding of the rationale of language teaching and learning and backed up by practical experience lies at the base of evaluation procedure (ibid: 74). Still there is danger of subjectivity in the assessment of course-materials that can be avoided by making both subjective analysis and objective analysis.

Thus, teachers can adapt teaching materials to fit their purpose by reorganizing the sequence of the topics. He can rearrange the lesson according to the grade and adaptability of the learners. A set of good course books or ELT materials allow adaptation to a certain degree to establish a balanced teaching and learning situation.

Course books are inevitable elements in all academic as they play the role of a model; they supply ready-made examples and practice sections which save teachers' energy and time; they provide sense of security to the learners in that they think their learning process becomes developed with the gradual advancement of the course. Most course books are designed considering the factors mentioned earlier. Publishers and materials designers are careful enough to give them a universal 
appearance. Thus, uniformity of lessons' coherence and concurrence of language items, supporting materials for all types of users are considered. Modern course books are enriched with all supporting materials such as teachers' guide, tape-scripts, video- records, self study workbooks etc. For this reason, teachers and learners still rely on commercially produced ELT materials. It does not necessarily mean that they are negligent to the checklists and the biased nature of some of the course materials. Rather, the easy accessibility, low cost, diversified but relevant subject areas which are quite rare in teacher-made materials, user friendliness, predictability of the minimum outcome, universal acceptance etc. contribute a lot to make the materials compatible. Moreover, materials design and teaching English are not alike. They require some individual skills and experiences besides the identical ones. According to Allwright (1982:6),

We need teaching materials as carriers of decisions best made by someone other than the classroom teacher, not because the classroom teacher is deficient, as a class teacher, but because the expertise required for materials writers is importantly different from that required of classroom teachers- the people who have the interpersonal skills to make classroom good places to learn in'.

In our teaching situation where there are very few trained teachers and available recourses and the personally developed ELT materials are unsystematic and unreliable, commercially published ELT materials still contribute as great facilitators to the users. What teachers and learners need to do is just to select, evaluate and adapt the lessons or materials according to their individual needs considering the factors mentioned earlier.

\section{Evaluation of the materials:}

In this section, I will try to evaluate different sections of 'Foundation English Course-Books 1 \& 2' a course book published by the Department of English Language and Literature for the use of undergraduate students at International Islamic University Chittagong. It is relevant here to give a brief description of the students who study here. After passing the Higher Secondary Certificate examination in Bangla medium, students get themselves enrolled in universities for higher education where the medium of study is English in most cases. 
It is regretful enough that students aiming at higher education are not proficient enough in English and thus fail to follow their class-lectures and textbooks. To create a congenial atmosphere for this students 'Foundation English Course' has been introduced for the first semester students and is continued to the next semester.

Book-1 of the course is recommended for the first semester students. The book is divided into two parts English Morphology and Syntax. In the Morphology section word formation, nouns and adjectives, phrasal verbs and mechanics of writing are discussed one after another. The syntax part focuses on the grammatical or the structural properties of English and the morphology part focuses on reading skills followed by a separate chapter on vocabulary. In the syntax section structural components such as sentence elements, Basic Sentence Patterns, Verbs, Verbal, Tense etc. are discussed intensively. The reading section provides thirty five reading passages with exercises on them. The Vocabulary section familiarizes different vocabulary items such as living space, personal matters, family and friends, food and drink, etc.

Book-2 is also divided into two parts namely 'Writing Skill' and 'Listening and Speaking Skills'. In the writing section students are introduced to basic writing i.e. making sentences, using punctuation marks, sentence sequencing etc. It is followed by another chapter named 'Intermediate Writing' which introduces formal and creative writing skills such as writing paragraphs, essays, messages, describing a place, CV or resume writing, writing about hypothetical situations and so on. In the listening and speaking skills section listening is introduced first selecting listening practice items like Apartments for Rent, Hotel Reservations, Travel arrangements, A University Degree, Interview of an English teacher and so on. The vocabulary section concentrates on meetings and greetings, apologies, agreement and disagreement, expression of opinions etc. The preface clarifies that the materials for the book have been compiled from a variety of sources, keeping in mind students' level of proficiency, the effectiveness of the materials as well as providing interesting and stimulating texts to promote the acquisition of English.

A close look at the table of contents will demonstrate the features of the books. The designers considered the best suitable approaches and methods for the students by following predictive and post-evaluation processes of materials used earlier by them. They have developed individual items, selected items from available resources and added 
lessons from different sources and adapted them on the basis of the needs assessment. Keeping the basic things to remember, they compiled the books with additional care on the ELT context in Bangladesh. Grammar items are introduced deductively as the inductive process seems to create confusion among students who have been familiarized with the deductive teaching and learning approach traditionally. Moreover, teachers and students think that it saves their time and energy.

After a discussion of a specific grammar or morphological item, an exercise section constructed by filling in the blanks, matching, completing sentences, joining sentences etc. is visible after every lesson in the Morphology and the Syntax section. The reading comprehension passages are followed by practice items like multiple choice questions, filling in the blanks, saying whether the statement is true or false, etc. The vocabulary items are taught through practicing them by filling in the blanks, correction, collocation, completing sentences etc. The writing section provides samples first and then analyses the samples and finally instructs students to develop their own writing as directed. Here, too, the use of filling in the blanks, joining sentences, guided writing, and free writing practice exercises are provided. In the listening classes students are introduced to a lesson after doing some pre-listening exercises. Then they listen to the recorded lesson and match that with the tape-script later. Finally, they complete the post-listening exercises like filling in the blanks, matching and summarizing. In the spelling lessons, students are introduced to the ways of spelling in different situations with examples. Later they are instructed to participate in the speaking exercise sections by sharing their ideas, making dialogues, delivering speeches etc.

From this critical analysis, it is clear that these books differ from the commonly neglected published materials which are disorganized, unfamiliar regarding the approaches and methods of teaching and learning, inflexible, uninteresting and above all, culture biased. These books have been appreciated by all sorts of users for their compatibility. These books have some weaknesses too. For example, the lessons are time consuming in the sense that some of the lessons demand more than ninety minutes, though the allotted time for each lesson is ninety minutes. Despite the limitations, these materials have been found useful rather than being simply 'rubbish' or aiming at just money-making. 


\section{Conclusion:}

ELT materials are the 'invisible hearts' of any ELT situation. If they are selected properly that reflects the requirements of the teachers and learners and if they are aimed at developing specific skills of the learners, they are more suitable than the personally produced materials. Target needs and learning needs should not be biased by discriminative items on gender, culture, race and nationality issues. But these biases do not make the published ELT materials negligible altogether. Teachers can adapt the potential offensive lessons by censoring in different ways as the research carried on by Gray (2000) suggests. In fine, it can be said that Brumfit (1979) has vital points to claim that commercially published materials are masses of rubbish. However, this generalized notion does not fit all the publications available commercially.

\section{Bibliography:}

Allwright R.(1982). 'What Do we want teaching materials for?' ELT Journal 36/1: 5-

Block, D. (1991). 'Some thoughts on DIY materials design'. ELT Journal 45/3: 211-217

Brumfit, C. J. (1980). 'Seven Last Slogans.' Modern English Teacher 7/1: 3031

Cunningsworth, A. (1995). Choosing Your Coursebook'. Macmillan Heineman.

Dow , F. (2004). 'Evaluating Classroom Teaching Materials' available on http//www.wheaton. edu/ bgc/ ICCT/ Resendlinks/ evaluating. html on $15 / 11 / 2010$.

Gray, J.(2000). 'The ELT coursebook as cultural artifact: how teachers censor and adapt' ELT Journal 54/3:374-377

Greenall, S.( 1984). 'The coursebook credibility gap.' EFL Gazette 53/54: 14

Harmer.J(2001).Coursebooks- A human, cultural and linguistic disaster?' Modern English Teacher 10/3:5

Howard,J. and Major, J.(2004). 'Guidelines for Designing Effective English Language Teaching Materials'. The TESOLANZ Journal, 12, pp.50-58 
Hutchinson, T. \& E. Torres (1994). 'The Textbook As An Agent of Change.' ELT Journal 48/4

McDonough, J and Shaw, C. (2003). Materials and Methods in ELT ( $2^{\text {nd }}$ Edition). Blackwell Publishing.

Nunan, D. (1991).Language Teaching Methodology.Prentice Hall.

O'Bannon, B. (2002). 'Planning for Instruction'. Available at http//itc.utk.edu/ bobannon/objectives.html on 18/12/2009.

Nunan, D. (1991).Language Teaching Methodology.Prentice Hall.

Sheldon, L. E.(1988).'Evaluating ELT Textbooks and Materials.'ELT Journal 42/4 pp237-46.

Williams, D (1983). 'Developing criteria for textbook evaluation.' ELT Journal 37/3: 251-255 